\title{
Founder Governance and Corporate Performance: An Empirical Analysis Based on Chinese Internet Listed Companies
}

\author{
Lin $\mathrm{Xu}^{1, *}$, Wei Yue ${ }^{2}$ and Hongtao $\mathrm{Xu}^{3}$ \\ ${ }^{1}$ International Business Faculty, Beijing Normal University Zhuhai Campus, Zhuhai, 519080, China \\ ${ }^{2}$ School of Business, Macau University of Science and Technology, Macau, 999078, China \\ ${ }^{3}$ School of Business, Macau University of Science and Technology, Macau, 999078, China \\ ${ }^{*}$ Corresponding author
}

\begin{abstract}
The study of the relationship between the founder of governance and corporate performance in recent years attracted academic attention. Based on the sample of 2010-2016 years Internet listed companies in Shanghai and Shenzhen stock markets, this paper validates the relationship between founder governance and corporate performance through the construction of empirical model, and finds that the increase of founder's shareholding ratio can improve the financial performance of Internet listed companies, but it has nothing to do with market performance. The founder's senior management can improve the financial performance of the enterprise, but it has nothing to do with the market performance. At last, this paper gives some suggestions for improving the founder governance and corporate performance improvement of Internet companies.
\end{abstract}

Keywords-Internet listed companies; founder; corporate governance; corporate performance

\section{INTRODUCTION}

The current country vigorously develops the digital economy, called "Widespread entrepreneurship and innovation", and Internet companies are not only the main force to promote the development of the digital economy, but also cultivate and bring up a large number of innovative entrepreneurs. By the end of 2017, the number of internet companies listed inside and outside China has reached 102, and the total market capitalization of these companies is close to 9 trillion yuan. The founder and his team, as the core resources of internet companies, have created huge wealth for their shareholders with their unique abilities. Therefore, it is of great significance to study the impact of founder governance on corporate performance.

\section{LITERATURE REVIEWS}

Founders can participate in corporate governance through shareholding or acting as an executive. Some scholars believe that the founder shareholding can promote the performance of the company, because when the founder holds a higher proportion of the company, it will send a positive signal to the external market, investors will give the firm a higher valuation, and can reduce the reverse choice of investors (Brennan \& Franks, 1997; Prasad, Bruton \& Vozikis, 2000). However, some scholars believe that the founder shareholding will have a negative impact on the performance of the enterprise, because when the founder is a large shareholder, it will produce private interests, which may damage the interests of small and medium shareholders and lead to a decline in the performance of the company (Song Zengji, 2013; Wu Lidong, 2016). Fahlenbrach (2009) proposes that if the founder is the CEO of the company, the company will have a higher market value. However, some scholars study found that the skills of the founders themselves may not be suitable for managing listed companies, so when they serve as company executives will have a negative impact on the corporate performance (Daily \& Dalton, 1992; Adams et al., 2009). Study on the internet corporate governance is still relatively small, and mainly focus on the business model (Zott \& Ami, 2007), value assessment (Schwartzeduardo \& MoonMark., 2010), merger and acquisition (Wang Xiuli and Liu Zijian, 2014) and other issues. In summary, previous research on the relationship between founder governance and enterprise performance did not form a unified view, which may be related to the sample, the variable selection of different, and based on the China internet business is very rare. Therefore, this paper takes 2010-2016 years of China's Internet listed companies as research samples, to explore the influence of Founder governance on corporate performance, in order to improve the corporate governance of China's Internet companies, enhance the company's performance has important significance.

\section{THEORY AND HYPOTHESES}

The level of corporate performance can measure the level of corporate governance to a certain extent. Previous studies mainly measure the corporate performance from two aspects: the first is the financial performance, which mainly reflects the short-term performance of the enterprise in the financial report, and the two is the market performance, which mainly reflects the long-term performance of the enterprise by evaluating the value of the company. This paper will analyze the relationship between founder governance and corporate performance from two aspects: financial performance and market performance.

China's stock market does not allow dual equity companies to go public. the founder of the Internet enterprise needs to hold a high proportion of equity in order to avoid the control right in the hands of the outside, and it can also guarantee the stability of the structure of the management team and the continuity of the enterprise strategy, thus it is beneficial to the improvement 
of the financial performance of the enterprise. However, the Internet enterprises need a large amount of funds at the initial stage. If the founder holds a high proportion of equity, it may restrict the investment of the external investors, and the external investors can not only bring capital resources to the enterprises, but also bring many industrial resources to the enterprises, and promote the enterprise for a long time from the strategic level. Therefore, the higher shareholding ratio of founders is unfavorable for enterprises to improve their market performance. Based on the above analysis, the following hypotheses are proposed.

H1: The shareholding ratio of founder of Internet companies is positively related to the company's financial performance.

H2: The shareholding ratio of founder of Internet companies is negatively related to the company's market performance .

Compared with other industries, the Internet industry has higher professionalism and most of the employees have been better educated. This makes the founders of the Internet business have good expertise and management skills. Therefore, the founder of the Internet business is beneficial to the improvement of the financial performance of the Internet enterprises. There are great differences in the scale of enterprises in the Internet industry, such as Alibaba, Jingdong, Tencent, and a small number of large enterprises, and the vast majority of the scale is small. Therefore, the possibility of merger and acquisition in the development process of small and medium Internet enterprises is greatly improved, which makes the founder concurrently executives will devote more time and energy, and will pour all the resources to ensure they founded the company can survive, growth, development and market in the fierce competition in the market. Therefore, as the founder of CEO tend to be more from a long-term perspective to consider for the company, rather than the non founder CEO due to performance pressure, will tend to be more concerned about the short-term return on investment. Based on the above analysis, the paper puts forward the following hypotheses:

H3: The founder of the Internet company serving as an executive is positively related to the company's financial performance.

H4: The founder of the Internet company serving as an executive is positively related to the company's market performance.

\section{Methodology}

\section{A. Sample Source}

This paper is based on 54 Internet Companies listed in Shanghai and Shenzhen two cities in 2010-2016 years, and pich out the Internet business revenue ratio has not yet reached $50 \%$ and the ST of the listed companies, obtained 46 Internet Companies data. This paper mainly adopts the Wind database, Shanghai stock exchange and Shenzhen stock exchange provided in the annual report, the prospectus related data were analyzed.

\section{B. Variable Definition}

In this paper, return on assets (ROA) is used to measure the financial performance, and Tobin'Q (TBQ) is used to measure the market performance. Founder shareholding ratio (FS), by looking at the annual report and prospectus of each sample enterprise, can find out the company's founder and the share of the share of information. Founder Executive (FE), which is the founder of the enterprise as chairman or CEO, if any post of chairman of the enterprise and the enterprise CEO by the founder or team, is the founder of executives identity value is 1 , otherwise 0 . Many factors can affect the performance of the company, the enterprise size (SIZE), enterprises listed years (AGE), financial leverage (LEV), the proportion of independent directors (INP), ownership concentration (CR) as control variables. The specific variable definition is shown in Table 1.

\section{Model Establishment}

In order to verify hypothesis 1 and hypothesis 2, model (1) is established:

$$
R O A(T B Q)=\alpha_{i}+\beta_{1} \times F S+\beta_{2} \times \text { Control_Variablesit }+\delta_{i t}
$$

In order to verify hypothesis 3 and hypothesis 4 , model (2) is established:

$$
R O A(T B Q)=\alpha_{i}+\beta_{1} \times F E+\beta_{2} \times \text { Control_Variables } i t+\delta_{i t}
$$

\section{DATA ANALYSIS}

\section{A. Descriptive Statistics}

Descriptive statistical analysis, as shown in Table 1, shows that the financial performance gap between the Internet listed companies is relatively large, and some companies are still in the first unprofitable state, and the market performance is more different, but all are positive, indicating that the market has a high degree of recognition for Internet companies. The shareholding ratio of the Internet company founder is uneven distribution. In the control variables, the size of the listed Internet companies, the companies listed years, the ratio of assets to debt and the concentration of equity are quite different, but in general, the ratio of assets and financial leverage is not high, which may be related to the high risk of the Internet industry.

TABLE I. DESCRIPTIVE STATISTICS

\begin{tabular}{|c|c|c|c|c|}
\hline Variable & Min & Max & Mean & Std \\
\hline ROA & -0.239 & 0.482 & 0.057 & 0.076 \\
\hline TBQ & 0.948 & 35.903 & 7.128 & 6.326 \\
\hline FS & 0.065 & 0.598 & 0.310 & 0.130 \\
\hline FE & 0 & 1 & 0.583 & 0.495 \\
\hline LNSIZE & 19.560 & 24.196 & 21.457 & 0.916 \\
\hline AGE & 1 & 25 & 4.457 & 4.582 \\
\hline LEV & 0.033 & 0.886 & 0.302 & 0.207 \\
\hline INP & 0.333 & 0.667 & 0.383 & 0.058 \\
\hline CR & 0.045 & 0.632 & 0.288 & 0.129 \\
\hline
\end{tabular}




\section{B. Regression Analysis}

The regression results are shown in Table 2. The founder shareholding ratio of internet listed companies is positively correlated with financial performance, and the relationship with market performance is not significant. Hypothesis 1 passes validation, Hypothesis 2 fails validation. The founder's executive is positively correlated with the financial performance, and the relationship with the market performance is not significant. Hypothesis 3 passes validation, Hypothesis 4 fails validation. In addition, to improve the financial leverage will reduce the Internet company financial performance, increasing the proportion of independent directors to improve corporate governance, improve company financial performance, ownership concentration increased to promote the role of the Internet financial performance and market performance.

TABLE II. REGRESSION ANALYSIS

\begin{tabular}{|c|c|c|c|c|}
\hline \multirow{2}{*}{ Variable } & \multicolumn{2}{|c|}{ Model (1) } & \multicolumn{2}{c|}{ Model (2) } \\
\cline { 2 - 5 } & ROA & TBQ & TBQ \\
\hline FS & $0.123189^{* *}$ & -12.67131 & & -0.622123 \\
\hline FE & & & 0.007212 & $-4.589356^{* * *}$ \\
\hline LNSIZE & 0.008813 & $-4.502504^{* * *}$ & -0.002330 & $1.950675^{* * *}$ \\
\hline AGE & -0.001149 & $1.880632^{* * *}$ & $-0.079751^{* * *}$ & 5.782044 \\
\hline LEV & $-0.059871^{*}$ & 5.658341 & $0.263448^{* *}$ & 10.90927 \\
\hline INP & $0.270435^{* *}$ & 6.168317 & $0.171506^{* * *}$ & $16.39135^{*}$ \\
\hline CR & $0.270435^{* * *}$ & $16.82454^{* *}$ & & \multirow{2}{*}{ RoA } \\
\hline
\end{tabular}

\section{CONCLUSIONS AND SUGGESTIONS}

\section{A. Conclusions}

From the descriptive analysis, the shareholding ratio of the Internet listed companies' founder was significantly lower than the GEM listed companies, which may be related to Internet Co in the start-up and growth stage on the amount of money demand and the introduction of other equity investors diluted share ownership of the founder. From the results of Internet governance, increase the shareholding ratio of the listed company founder is beneficial to the improvement of financial performance, but it has inhibitory effect on the market performance of listed companies, the Internet founder concurrently executive is beneficial to the improvement of financial performance, but it has not significant to market performance. This shows that in the Internet industry founder generally have its unique value, and this unique value has played a certain role in corporate governance, but because of the performance of listed companies required pressure, founder of pay more attention to short-term financial performance.

\section{B. Suggestions}

The rational planning of ownership structure and control power can attract external capital, provide more industrial resources for the long-term development of enterprises, and avoid the outflow of control right, which can motivate the founders and their team to exert their talents and promote the performance of enterprises. The success of the Internet enterprise is inseparable from the ability of the founders and their teams. Therefore, the optimization of the structure of the founders and their teams and the establishment of long-term development goals are not only conducive to the full play of the enterprise, but also to improve the short-term financial performance of the enterprise, but also to improve the long-term performance of the enterprise. Effect. The dual equity system should be introduced at the right time to perfect the supporting system of relevant laws and regulations. At present, China's capital market and legal environment is not mature, the full implementation of the dual ownership system may lead to excessive market reaction and greater risk, so the proposed classification step by step way the gradual liberalization of the system, can be the first trial in the Internet industry. Before the reform of the dual ownership system, the relevant legislation and regulatory agencies first perfected the supporting mechanism and legal system arrangement, including the protection series of small and medium investors, the compulsory information disclosure system, the non judicial relief machine system, the securities collective litigation system, the restriction of the transfer of multiple voting stock shares and the restriction of the multiple voting rights. The voting field and dividend rights of the stock.

\section{ACKNOWLEDGEMENT}

This research was financially supported by the teachers' research capability promotion plan of Beijing Normal University Zhuhai Campus (project number: 201850005).

\section{REFERENCES}

[1] Brennan M. J. , \& Franks. Underpricing, ownership and control in initial public offerings of equity securities in the UK, Journal of Financial Economics[J]. 1997, 45, 391-413.

[2] Prasad, D., Bruton, G.D \& Vozikis,G. Signaling value to business angels: The proportion of the entrepreneur's net worth invested in a new venture as a decision signal [J]. Venture Capital, 2000, 2, 167-182.

[3] Song Zengji, Wang Hongjun \& Zhang Zongyi. Research on the relationship between founder characteristics, shareholding and company performance of high-tech enterprises [J]. science and technology progress and countermeasures, 2013,30 (07): 90-96.

[4] Wu Lidong, Ding Haojie \&Wang Kai. The founder of characteristics and corporate governance mechanism in private enterprises to improve the management of the $[\mathrm{J}]$. journal, the influence degree of the occupation managers introduced in 2016, 13 (4): 505-515. 
[5] Fahlenbrach R. Founder-CEOs, Investment Decisions, and Stock Market Performance[J]. Social Science Electronic Publishing, 2009, 44(2):439-466.

[6] Daily, C.M., D.R.Dalton. Financial Performance of Founder-Managed versus Professionally Managed Corporations[J]. Journal of Small Business Management, 1992, 30, 25-34.

[7] Adams R.B., Almeida H.,\& Ferreira. D. Understanding the Relationship between Founder-CEO and Firm Performance[J]. Journal of Empirical Finance, 2009, 16, 136-150.

[8] Zott, C., \& Amit, R. Business Model Design and the Performance of Entrepreneurial Firms, 2007.

[9] Schwartzeduardo, S., \& Moon Mark. Rational pricing of internet companies. Financial Review, 2010, 36(4), 7-26.

[10] Wang Xiuli and Liu Zijian. Research on strategic mergers and acquisitions and financial synergies of Internet companies -- Based on a case study of Baidu merger and acquisition. Journal of Beijing Technology and Business University (SOCIAL SCIENCE EDITION), 2014, 29 (6), 47-54. 